\title{
The field of research in mathematics teacher education
}

\author{
O. Chapman
}

Published online: 21 July 2011

(C) Springer Science+Business Media B.V. 2011

The field of research in mathematics teacher education has grown substantially since the establishment of the Journal of Mathematics Teacher Education [JMTE]. Thanks to the vision of the founding editor-in-chief, Tom Cooney, and the work of the editors-in-chief who followed (Barbara Jaworski and Peter Sullivan) and their editorial teams for making this possible. In particular, as I take over from Peter as editor-in-chief, we (his current team of editors) will like to acknowledge his outstanding contribution and leadership. The following is a direct quote composed jointly by the Associate Editors (Anne Cockburn, João Pedro da Ponte, Margaret Walshaw, Orit Zaslavsky).

We were delighted and highly honored when Peter asked us to become Associate Editors of JMTE. Under his leadership, the journal has gone from strength to strength making it an excellent resource for mathematics teacher educators and researchers around the world. Thanks to Peter's extensive knowledge, rigorous attention to detail, and outstanding qualities as a mentor. Many have benefited from his wisdom and guidance. Due to his keen interest in researchers across the world and in the work they are all doing in relation to teaching mathematics, the journal has become even more international. His unflappable, supportive, and friendly disposition made the work in the Journal a real pleasure. We owe him a great debt.

As an associate editor under Peter, I share the same sentiments. I am honored by and highly appreciative of his confidence in me to take over the editor-in-chief and his care in helping me to make the transition. Thank you Peter for laying a solid foundation for me to build on. We, the editorial team, are committed to continue to maintain the high standards of the journal that have been established. We are honored to have the ongoing support of our editorial board and reviewers whose valuable contribution will help to make this happen.

As we move forward, one of our goals will be to examine the scope of the journal. The field of research on mathematics teacher education as currently represented in JMTE is much broader than the name of the journal suggests. Mathematics teacher education could imply a focus on the programs, tools/tasks, and processes used to prepare prospective

O. Chapman $(\bowtie)$

University of Calgary, Calgary, Canada

e-mail: chapman@ucalgary.ca 
teachers and further develop professionally practicing teachers. However, while this is a significant focus of the articles in JMTE, there is also an emphasis on the mathematics teacher, that is, overall, there is a focus on the mathematics teacher and mathematics teacher education. While these two are connected, research goals could focus on them in distinct ways. Studies on the mathematics teacher include a focus on teachers' beliefs, conceptions, identity, mathematics knowledge, mathematics knowledge for teaching, pedagogical knowledge, and practice. The underlying assumption of such studies is that they inform mathematics teacher education, thus their relevance to JMTE. However, it is important for researchers to make explicit this connection based on evidence from their research. Too often, initial submissions of manuscripts I have reviewed for JMTE over the last decade tend to place little emphasis on this.

The field is also growing in relation to research on mathematics teacher educators in a way that parallels that of the mathematics teacher. The response to the call for manuscripts for the JMTE Special Issues on Mathematics Teacher and Mathematics Teacher Educator Change was beyond expectation. Some of the articles in these two issues suggest the need for the field to also grow in its research methods to deal with situations such as a professional learning community in which the teacher educator's role evolves as researcher, facilitator, and learner without the use of a pre-planned research process based on established standards. In a forthcoming chapter on "Research methods in mathematics teacher education" (Gellert et al. 2012) in the Third International Handbook of Mathematics Education (Springer), we discuss a version of participatory action research as an example of a different research approach relevant to the field of mathematics teacher education. The growth and importance of the field is also evidenced by the International Congress on Mathematical Education for the first time in 2012 including a topic study group on inservice education, professional development of mathematics teachers and one on preservice mathematical education of teachers.

In this issue of JMTE, the four articles provide a sample of the scope of the journal and the field in relation to their focus on the teacher and on supporting teacher learning. They include both prospective and practicing teachers and deal with teachers' reflective activity, theoretical tools to support teachers' reflection, technological pedagogical content knowledge, and teachers' use of curriculum materials.

The importance of reflection in teachers' planning and learning can be implied from the articles by Thomas Ricks and Maria Mellone. However, the two are different in their use of reflection as a construct. Ricks discusses teacher reflection in terms of two categories: (1) incident reflection that occurs as specific incidents or episodes unconnected to future activity and (2) process reflection that connects reflective incidents into a cyclic progression that refines ideas through experimental action. He examines the reflective activity of a group of prospective secondary mathematics teachers as they jointly planned a public school lesson to illustrate how incidents of reflection can be refined and linked into more powerful and purposeful progressions of ideas. Mellone addresses reflection in terms of noticing. She examines the conjecture that theoretical tools suitably chosen can help the teacher to make assumptions about the construction of knowledge and the nature of mathematics explicit and support the teacher's reflection on his or her practice. Based on a case study of one teacher, she shows how an epistemological vision of mathematics in resonance with a model of cognitive dynamics can work as a powerful tool to support a teacher's stable and autonomous attitude of noticing and influence his or her teaching.

The importance of technology and curriculum materials in understanding the teacher and implication for teacher education is implied in the articles by Janet Bowers and Jeffrey Choppin. Bowers suggests that the heart of sound technological implementation is to 
encourage students to use whatever tools are available to explain the mathematical relations that underlie what they observe on the screen. She suggests ways in which technological pedagogical content knowledge may be customized to provide a framework for guiding prospective teachers' efforts to develop and assess lesson plans that use technology in novel and effective ways. She uses two contrasting case studies to illustrate the differing degrees to which prospective mathematics teachers leveraged technology to teach themselves and their future students to explain the mathematics behind various topics. Choppin focuses on teachers' use of curriculum materials for three teachers who had enacted instructional sequences from the materials on multiple occasions. He discusses how the teachers drew on the materials, what they understood about the curriculum resources, and how they connected their use of the materials to their observations of student thinking. He points out the similarities across the teachers with respect to their goals and how they read and followed recommendations in the teacher resource materials and the differences in how their task revisions were in response to what they observed about student thinking.

While these articles do not add to the scope of the field, they do add to the depth by offering interesting ways to think about three important aspects of teacher education; reflection, technology, and curriculum materials. These are areas that have ongoing relevance for research as we continue to work toward helping teachers to transform the mathematics classroom to twenty-first century perspectives.

\section{Reference}

Gellert, U., Chapman, O., \& Becerra, R. (2012). Research methods in mathematics teacher education. In A. Bishop, M. Clements, C. Kietel, J. Kilpatrick, \& F. Leung (Eds.), Third international handbook of mathematics education. New York: Springer (forthcoming). 